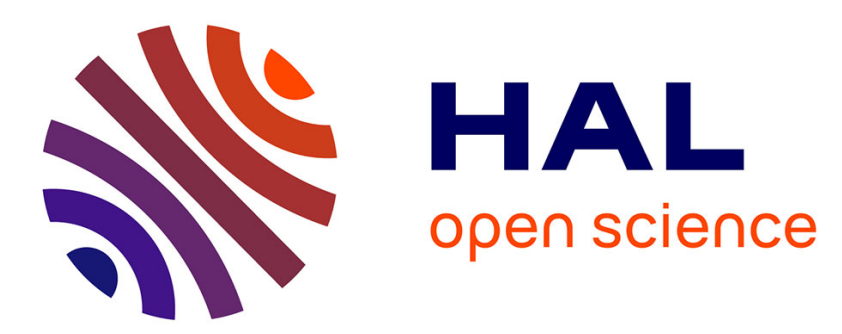

\title{
Laser locked cavity ringdown spectroscopy of the (31-) local mode band system of $\mathrm{H} 13 \mathrm{C} 13 \mathrm{CH}$
}

Joseph Guss, Markus Metsälä, Markku Vainio, Olavi Vaittinen, Lauri Halonen

\section{To cite this version:}

Joseph Guss, Markus Metsälä, Markku Vainio, Olavi Vaittinen, Lauri Halonen. Laser locked cavity ringdown spectroscopy of the (31-) local mode band system of $\mathrm{H} 13 \mathrm{C} 13 \mathrm{CH}$. Molecular Physics, 2007, 105 (05-07), pp.807-813. 10.1080/00268970601129068 . hal-00513068

\section{HAL Id: hal-00513068 \\ https://hal.science/hal-00513068}

Submitted on 1 Sep 2010

HAL is a multi-disciplinary open access archive for the deposit and dissemination of scientific research documents, whether they are published or not. The documents may come from teaching and research institutions in France or abroad, or from public or private research centers.
L'archive ouverte pluridisciplinaire HAL, est destinée au dépôt et à la diffusion de documents scientifiques de niveau recherche, publiés ou non, émanant des établissements d'enseignement et de recherche français ou étrangers, des laboratoires publics ou privés. 


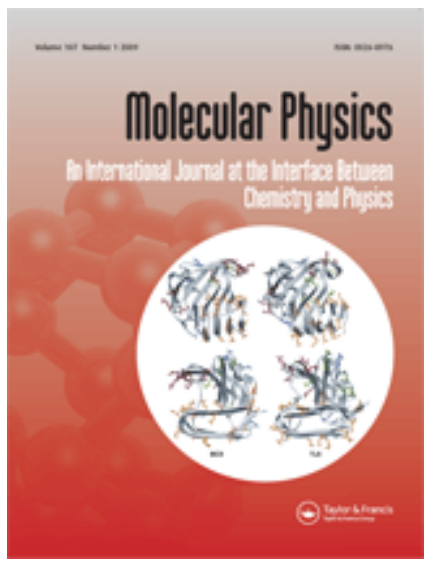

\section{Laser locked cavity ringdown spectroscopy of the (31-) local mode band system of $\mathrm{H}^{13} \mathrm{C}^{13} \mathrm{CH}$}

\begin{tabular}{|c|c|}
\hline Journal: & Molecular Physics \\
\hline Manuscript ID: & TMPH-2006-0056.R1 \\
\hline Manuscript Type: & Full Paper \\
\hline $\begin{array}{r}\text { Date Submitted by the } \\
\text { Author: }\end{array}$ & 07-Nov-2006 \\
\hline Complete List of Authors: & $\begin{array}{l}\text { Guss, Joseph; University of Helsinki, Laboratory of Physical } \\
\text { Chemistry } \\
\text { Metsälä, Markus; University of Helsinki } \\
\text { Vainio, Markku; University of Helsinki } \\
\text { Vaittinen, Olavi; University of Helsinki } \\
\text { Halonen, Lauri; University of Helsinki }\end{array}$ \\
\hline Keywords: & cavity ringdown, local modes, acetylene, intensities, Herman-Wallis \\
\hline
\end{tabular}

\section{s ScholarONE" \\ Manuscript Central}




\title{
Laser locked cavity ringdown spectroscopy of the (31-) local mode band system of $\mathrm{H}^{13} \mathrm{C}^{13} \mathrm{CH}$
}

\author{
Joseph Guss, Markus Metsälä, Markku Vainio, Olavi Vaittinen, Lauri Halonen* \\ Laboratory of Physical Chemistry, P.O. Box 55 (A.I. Virtasen aukio 1), FIN-00014 University of Helsinki, Finland \\ (Received 00 Month 200x; In final form 00 Month 200x)
}

\begin{abstract}
In this article we present the spectrum of $\mathrm{H}^{13} \mathrm{C}^{13} \mathrm{CH}$ near $13000 \mathrm{~cm}^{-1}$ and its ro-vibrational analysis. Our high repetition rate cavity ringdown spectrometer was used to record the spectrum. Seven vibrational bands, including six to previously unobserved vibrational states, were recorded and rotationally analysed. The band origin of the cold $3010^{0} 0^{0}$ stretching vibrational combination transition $((31-)$ in the local mode notation) was measured at $12960.28807(38) \mathrm{cm}^{-1}$. The vibrational transition dipole moments were determined through intensity measurements of the spectral peaks. The values of the unperturbed vibrational transition dipole moment, $\left|R_{\mathrm{v}^{\prime} \mathrm{v}^{\prime \prime}}\right|^{2}$, and the first Herman-Wallis coefficient, $A_{1}$, for the $3010^{0} 0^{0}$ band were found to be $1.1570(26) \times 10^{-9} D^{2}$ and $-9.5(6) \times 10^{-4}$, respectively. The numbers in parentheses represent one-standard error in the least significant digits.
\end{abstract}

\section{Introduction}

Acetylene is a widely used molecule in chemical synthesis, oxyacetylene gas welding, and as a carbon source in the production of carbon nanotubes $[1,2]$. It is also of importance in theoretical and computational chemistry where, for example, it is a benchmark molecule in the optimisation of high-level electronic structure calculations [3]. Variational methods, in which rotational and vibrational energy levels are computed, frequently target small molecules. Acetylene is a good candidate for such attention as it is arguably the simplest four-atom molecule [4]. It has a low density of states due to its linear geometry and light nuclei, and for these reasons acetylene is also a frequently used test molecule for high-resolution spectroscopy. As a result, there is a wealth of experimental data to compare with the theoretical models.

The near-infrared and visible spectra of acetylene are dominated by stretching vibrational overtone bands. The strongest transitions are usually those to the states labelled in the local mode notation as $(m 0-)$, where the vibrational quantum numbers $m$ and 0 refer to the two $\mathrm{CH}$ bond oscillators and the minus sign indicates that the vibrational wavefunction is antisymmetric in permuting the $\mathrm{CH}$ oscillators. There are weaker transitions to states of the type $(m n-)$, where both $m$ and $n$ are non-zero. Weaker still are the transitions to states that involve bending or CC stretching overtones. Generally, in addition to the main band, there are many weaker bands induced by vibration-rotation interactions between the upper states. Vibration-rotation state analysis therefore produces a lot of spectroscopic information. In the present contribution, we have examined the $(31-)$ band system of the $\mathrm{H}^{13} \mathrm{C}^{13} \mathrm{CH}$ isotopologue.

A simple local mode model has been applied to compute the stretching states of $\mathrm{H}^{13} \mathrm{C}^{13} \mathrm{CH}$ up to five quanta of $\mathrm{CH}$ stretch and and two quanta of CC stretch [5]. More recently, Herman et al. have performed more thorough normal mode theory based calculations of the vibrational energy level structure including all vibrational degrees of freedom [6]. They have computed energy levels up to $12000 \mathrm{~cm}^{-1}$. This model benefits from spectroscopic studies of $\mathrm{H}^{13} \mathrm{C}^{13} \mathrm{CH}$, particularly those investigations - such as this one- that examine the high overtone states for which less information exists.

Our measurements of the $\mathrm{H}^{13} \mathrm{C}^{13} \mathrm{CH}$ spectrum were recorded with a cavity ringdown (CRD) spectrometer. Cavity ringdown spectroscopy is a sensitive absorption technique that has found uses in a broad range of disciplines [7], many of them in the pure and applied spectroscopic fields [8,9]. The sensitivity inherent to the technique makes it suitable for studies of trace gases and weakly absorbing species. We have built

* Corresponding author.

Email address: lauri.halonen@helsinki.fi 
a CRD spectrometer that, through the use of active frequency stabilisation, achieves greater sensitivity than most standard CRD setups. Comparisons of our setup with other CRD systems are made in references [10] and [11].

\section{Experimental Setup}

Our high repetition rate CRD spectrometer has been described previously [10,11]. Broadly speaking, our setup has the appearance of a standard absorption experiment. The light source is the tunable continuous wave (cw) infrared beam from a Nd: $\mathrm{YVO}_{4}$ (Coherent Verdi) pumped Ti:Sapphire laser (Coherent 899$21)$, the sample cell is the ringdown cavity $(R=99.98 \%, L=30 \mathrm{~cm})$, and the detector is a photodiode (Hamamatsu S1223, battery biased). The ringdown cavity was filled with $\mathrm{H}^{13} \mathrm{C}^{13} \mathrm{CH}$ sample (99 atomic percent purity, $\mathrm{C} / \mathrm{D} / \mathrm{N}$ Chemicals) at a pressure of 8 torr. The pump laser power was roughly $8 \mathrm{~W}$ resulting in an infrared power of about $350 \mathrm{~mW}$ from the Ti:Sapphire laser. Approximately $2 \mathrm{~mW}$ of this was injected into the ringdown cavity with the remainder either being used for calibration $(\sim 30 \mathrm{~mW})$, or lost in the double pass of the acousto-optical modulator (AOM), as described below. Data from the detector are sent to a computer via a data aquisition card (14-bit, Strategic Test UF. 4021) for processing.

The heart of our setup, and the feature that distinguishes it from most other CRD spectrometers, is the active feedback locking system. The laser is frequency-stabilised with the ringdown cavity using the Pound-Drever-Hall technique [12]. On its way to the cavity, the laser beam passes through an AOM that is used to block the beam and to thereby initiate ringdown events. After a fixed delay in which the ringdown is recorded, the AOM is switched on again and the feedback system locks the laser to the maximum of a cavity fringe. This cycle is repeated at $10 \mathrm{kHz}$. The outcome is that at all times we are either injecting light into the cavity ("ring-up") or measuring a ringdown. As in other CRD experiments, the ringdown signal is fitted to an exponential decay to extract $\tau$, the decay time. The empty cavity decay time, $\tau_{0}$, is about $9 \mu$ s in the wavelength region $12850-13050 \mathrm{~cm}^{-1}$ examined in this study.

The frequency-stabilised setup has two advantages over the standard cw-CRDS configurations [13,14]: The laser has a greater coupling efficiency with the ringdown cavity and ringdown events can be recorded at a much higher repetition rate. Recording ringdowns at a high rate allows us to use more aggressive averaging in our data manipulation and to thereby achieve an overall greater sensitivity without having to resort to impractically slow scanning. A single $0.9 \mathrm{~cm}^{-1}$ scan takes less than two minutes with this system.

The range of an individual scan is limited to $0.9 \mathrm{~cm}^{-1}$ by the maximum displacement of the piezoceramic tube that holds one of the cavity mirrors. The change in cavity length is translated into a change in laser frequency as the stabilisation system tracks the frequency of a cavity fringe. Many such scans are concatenated to produce the complete spectrum. Each $0.9 \mathrm{~cm}^{-1}$ scan contains 1000 points and each of those points is the average of 1000 decays fitted to an exponential with the least-squares method. The spectra were calibrated as described in ref. [15]. Briefly, two transmission spectra are recorded simultaneously with the acetylene spectrum: $A n \mathrm{I}_{2}$ spectrum is used to calibrate the absolute wavenumber scale and the spectrum of a Fabry-Perot interferometer is used for linearisation. Occasionally, there are no assigned $\mathrm{I}_{2}$ lines within the $0.9 \mathrm{~cm}^{-1}$ scan range and overlapping acetylene peaks from adjacent scans are used for calibration instead. The absolute wavenumber accuracy of the final spectrum is determined by the quality of the iodine atlas [16] and is estimated to be better than $0.005 \mathrm{~cm}^{-1}$, based on fits to these and previously recorded data [11].

The design of our CRD spectrometer is constantly being modified to adapt to new experimental goals and to overcome problems. Using the AOM in a double-pass configuration [11] decreases the short-term $(1 \mathrm{~s})$ baseline noise in the recorded decay times by half. It also removes completely the sensitive dependence of ringdown times on the DC voltage supplied to the AOM. The largest remaining source of woe in our experiment is the baseline drift. While scanning, the measured value of $\tau_{0}$ changes gradually over the scan range by as much as $0.02 \mu \mathrm{s}$. This has been the subject of much speculation and the prime suspects for its cause are the scanning galvo plate in the Ti:Sapphire laser and the piezo-mounted mirror in the ringdown cavity. Off-axial motion of the cavity mirror could be caused by the cylindrical piezo bending under the weight of the mirror and its mount. A planned improvement to the setup, in which the piezo is mounted outside the cavity, may solve this problem. We intend to mount the mirror directly 
onto the end of the monolithic block and to make the seal with a thick o-ring. The piezo will be mounted on a bracket secured to the optical table and will press inward on the mirror, slightly compressing the o-ring, in order to scan. In this way, the piezo will support only its own weight and not the weight of the mirror and its mount. It is hoped that this modification will eliminate the off-axial motion of the end mirror.

\section{Spectroscopic Results}

Figure 1 shows the entire recorded $\mathrm{H}^{13} \mathrm{C}^{13} \mathrm{CH}$ spectrum from $12840 \mathrm{~cm}^{-1}$ to $13030 \mathrm{~cm}^{-1}$. The most prominent band in the spectrum is a transition to the local mode $\mathrm{CH}$ stretching state $(31-)$ which corresponds to the $3010^{0} 0^{0}$ state in the customary normal mode notation where the standard quantum numbers $\left(v_{1} v_{2} v_{3} v_{4}^{l_{4}} v_{5}^{l_{5}}\right)$ are used to label the vibrational states [17]. Seven much weaker transitions are also present. One is the $3010^{0} 0^{0}$ band of the $\mathrm{H}^{12} \mathrm{C}^{13} \mathrm{CH}$ isotopologue, which is present in our spectrum due to an impurity in the sample. It has been reported previously in more in-depth examinations of that isotopologue $[18,19]$. The remaining six bands have all been assigned as hot bands. These $\Pi-\Pi$ transitions arise from doubly degenerate lower states with a single quantum of $v_{4}$ or $v_{5}$. Several oxygen peaks, courtesy of a slow leak in the cavity, are also visible in the spectrum. It is difficult to decide what constitutes an unassigned line given that the distinction between very weak, but real, features and noise is subjective. Nevertheless, a conservative estimate puts the number of assigned lines in the spectrum at $70 \%$ of the total number of lines observed.

Figure 2 shows a small section of the spectrum with a greatly magnified vertical scale. Of note in this figure is the presence of the baseline drift mentioned in the Experimental section. The baseline gradually changes during each $0.9 \mathrm{~cm}^{-1}$ scan. The point at which a pair of neighbouring scans meet is located by the sudden jump in the baseline. All acetylene lines in the spectrum possess a Doppler-broadened width of roughly $0.026 \mathrm{~cm}^{-1}$.

\subsection{Vibrational and Rotational Results}

The vibration-rotation energy of a linear semirigid molecule can be expressed up to the fourth order as [17]

$$
\frac{E_{\mathrm{v}}}{h c}=G_{\mathrm{v}}+F_{\mathrm{v}}(J, k)=G_{\mathrm{v}}+B_{\mathrm{v}}\left[J(J+1)-k^{2}\right]-D_{\mathrm{v}}\left[J(J+1)-k^{2}\right]^{2},
$$

where $G_{\mathrm{v}}$ is the vibrational term value, $B_{\mathrm{v}}$ is the rotational constant, and $D_{\mathrm{v}}$ is the quartic centrifugal distortion parameter of the vibrational state characterised by the quantum label $v$. The quantity $J$ is the total angular momentum quantum number, and $k=l_{4}+l_{5}$ is the total vibrational angular momentum label with $l_{4}$ and $l_{5}$ being the vibrational angular momentum quantum numbers of the bending vibrations. Rotational analysis has been performed separately for each parity component of the doubly degenerate vibrational states. In order to calculate the upper state parameters with better accuracy, we have used reduced energy transitions. Both upper and lower state energies are reduced by the lower state rotational energy [20]:

$$
\nu_{r e d}=\Delta G+\Delta B\left[J^{\prime}\left(J^{\prime}+1\right)-k^{\prime 2}\right]-\Delta D\left[J^{\prime}\left(J^{\prime}+1\right)-k^{\prime 2}\right]^{2}
$$

where $\Delta G=G_{\mathrm{v}^{\prime}}-G_{\mathrm{v}^{\prime \prime}}, \Delta B=B_{\mathrm{v}^{\prime}}-B_{\mathrm{v}^{\prime \prime}}, \Delta D=D_{\mathrm{v}^{\prime}}-D_{\mathrm{v}^{\prime \prime}}$, and the single and double primes refer to the upper and lower states, respectively. The linear least-squares method is used to optimise the coefficients of the resulting polynomial expansion (which represents the reduced transition wavenumbers). The lower state parameters, which are known to high accuracy and are taken from ref. [21], are fixed during the optimisation.

Vibrational and rotational parameters were determined for the seven $\mathrm{H}^{13} \mathrm{C}^{13} \mathrm{CH}$ bands in the spectrum and are shown in Table 1. The upper states were vibrationally assigned with the aid of a calculation 
based on the parameters published by Di Lonardo et al. [22]. Their model takes into account the relevant perturbations and can be employed to predict a multitude of states in $\mathrm{H}^{13} \mathrm{C}^{13} \mathrm{CH}$. In addition to the eigenvalues, we also calculated the eigenvectors, from which the rotational $B$ constants are determined; these are also used to aid in the vibrational assignment of the upper states. Both the band origins of the transitions and the rotational constants agree well with the predicted values for all the assigned states. In all cases, the predicted transition energies are within $1.5 \mathrm{~cm}^{-1}$ of the measured values and the predicted $\boldsymbol{B}$ constants are within $5 \times 10^{-4} \mathbf{c m}^{-1}$. All the observed states are mixtures of two or more zeroth order states and we have given the two highest contributing states as an assignment in Table 1 . The lower states of the transitions were confirmed by the ground state combination difference method [17].

Inspection of the calculated upper state contributions (percentages in Table 1) reveals that a quartic anharmonic interaction, Darling-Dennison resonance, is a dominating influence as expected [23, 24]. According to this model, the $3010^{0} 0^{0}$ and $1030^{0} 0^{0}$ states are in strong resonance and become mixtures of the relevant basis functions. The local mode picture offers a different interpretation: Bond anharmonicity is the main reason for the energy separation of the (40-) and (31-) states (about $344 \mathrm{~cm}^{-1}[5]$ ) and the local mode basis functions are already close to the final eigenfunctions. Thus, it is justified to state that the local mode labels present a more physically appealing interpretation.

The strongest transition $\left(3010^{0} 0^{0}\right.$, or $(31-)$ in the local mode notation) has been previously observed in a photoacoustic experiment carried out by Hall in 1984 [25]. The values for $\Delta G, B^{\prime}$ and $D^{\prime}$ reported in that work do not quite agree with our results to within a three-standard error. However, all three parameters match to within a two-standard error when Hall's data are refitted with the more accurate ground state parameters from Di Lonardo et al. [22]. The values were determined more accurately in our experiment where the high signal-to-noise ratio allows for more accurate determination of the peak positions, and a larger number of rotational lines ( 75 versus 53) were measured. To our knowledge, the upper states of the hot bands had not been experimentally observed prior to this investigation.

The standard errors of the fits to the ro-vibrational data are in all cases smaller than the stated experimental uncertainty. Additionally, there is good agreement between the band origins of the e and f pairs, to within two-standard errors of the fitted values.

\subsection{Intensities}

Intensity measurements were not the primary aim of this investigation and were made difficult by a number of factors. Small changes in the cell temperature can have a large effect on the measured intensities, yet in this experiment the sample cell was not temperature-stabilised. As the measurements took place at all hours of the day for several days there were bound to have been some variations in the temperature. Most importantly, intensity measurements for all but the strongest observed band were made difficult by the aforementioned baseline drift. Because of this problem, the first step in our intensity measurement procedure is to visually inspect the peak in question and to subtract a linear baseline from it. In general, the baseline drift possesses a small second derivative and can be assumed to be linear over the width of a single spectral peak (see fig. 2). Problems arise when there are several nearby or overlapping peaks or when the baseline has a different gradient on either side of the peak. For this reason we present the data with an uncertainty in accuracy of up to $25 \%$. Having subtracted the linear baseline, we fit a Gaussian function to the rotational line and divide its area by the sample pressure, giving the linestrength $S_{J}$ (in $\left.\mathrm{cm}^{-2} / \mathrm{atm}\right)$ which is related to the square modulus of the vibrational transition dipole moment $\left|R_{\mathrm{v}^{\prime} \mathrm{v}^{\prime \prime}}\right|$ by $[26]$

$$
S_{\mathrm{J}}=A \frac{\tilde{\nu} C}{Q T} g^{\prime \prime} \times e^{\left(-h c E^{\prime \prime} / k T\right)}\left[1-e^{(-h c \tilde{\nu} / k T)}\right]\left|L_{\mathrm{J}}\right|^{2}\left|R_{\mathrm{v}^{\prime} \mathrm{v}^{\prime \prime}}\right|^{2}
$$

where $A$ is a constant equal to $3054.72 \mathrm{~cm}^{-1} \mathrm{~atm}^{-1} \mathrm{D}^{-2}, \tilde{\nu}$ is the wavenumber of the line, $T$ is the sample temperature in $\mathrm{K}, E^{\prime \prime}$ and $g^{\prime \prime}$ are the lower state rotational energy and degeneracy (including the statistical weight), respectively, $C=0.99$ is the stated purity of our isotopically enriched $\mathrm{H}^{13} \mathrm{C}^{13} \mathrm{CH}$ sample, $\left|L_{\mathrm{J}}\right|$ is 
the modulus of the Hönl-London factor of the transition, and $Q$ is the total internal partition sum. The partition sum is calculated at $293 \mathrm{~K}$ using the coefficients of the polynomial expansion given in ref. [6]. The Hönl-London factors are from ref. [27].

In each band, $S_{\mathrm{J}}$ was measured for as many rotational peaks as possible. Equation (3) was then used to extract $\left|R_{\mathrm{v}^{\prime} \mathrm{v}^{\prime \prime}}\right|$. Changes in the value of $\left|R_{\mathrm{v}^{\prime} \mathrm{v}^{\prime \prime}}\right|$ as a function of $J^{\prime}$ can indicate ro-vibrational perturbations; however, experimental uncertainty precluded such analysis for the weaker bands. Table 2 shows the averages of $\left|R_{\mathrm{v}^{\prime} \mathrm{v}^{\prime \prime}}\right|$ for each of the hot bands, grouped by rotational branch. As can be seen from the table, there is sometimes a small difference between the vibrational transition moments of the $\mathrm{P}\left(\Delta J=J^{\prime}-J^{\prime \prime}=-1\right)$ and $\mathrm{R}(\Delta J=1)$ branches of the same band. This may indicate the presence of a Herman-Wallis effect [28] due to ro-vibrational perturbations to the upper state of the transition; however, for the reasons outlined above, such a claim would be unsupported in light of our experimental uncertainty. The strongest band does however exhibit a Herman-Wallis dependence beyond such uncertainty, as can be seen in Figure 3. These measurements are from more intense lines and suffer less from the sources of uncertainty mentioned above. The intensities measured from this band possess an uncertainty of roughly $10 \%$. The measured value of $\left|R_{\mathrm{v}^{\prime} \mathrm{v}^{\prime \prime}}\right|^{2}$ decreases with increasing $m\left(m=-\left(J^{\prime}+1\right)\right.$ and $m=J^{\prime}$ for the $\mathrm{P}$ and $\mathrm{R}$ branches, respectively). This dependency was fitted by the linear least-squares method to the expression [29]

$$
\left|R_{\mathrm{v}^{\prime} \mathrm{v}^{\prime \prime}}\right|^{2}=\left|R_{\mathrm{v}^{\prime} \mathrm{v}^{\prime \prime}}^{0}\right|^{2}\left(1+A_{1} m+A_{2} m^{2}+\ldots\right)^{2},
$$

where $\left|R_{\mathrm{v}^{\prime} \mathrm{v}^{\prime \prime}}^{0}\right|^{2}$ is the vibrational transition dipole moment of the transition to the unperturbed upper vibrational level and the $A_{n}$ parameters are called the Herman-Wallis coefficients. It was found that the contributions of terms beyond $A_{1} m$ were negligible and eq. (4) was truncated accordingly. Fitting the $\left|R_{\mathrm{v}^{\prime} \mathrm{v}^{\prime \prime}}\right|^{2}$ values from the $3010^{0} 0^{0}$ band to eq. (4) yields $\left|R_{\mathrm{v}^{\prime} \mathrm{v}^{\prime \prime}}^{0}\right|^{2}=1.1591(25) \times 10^{-9} D^{2}$ and $A_{1}=$ $-8.7(7) \times 10^{-4}$ where the numbers in parentheses indicate one-standard error in the least significant digits. These results imply the presence of a perturbing state the identity of which remains unknown.

\section{Conclusions}

In this study, we have measured several transitions of $\mathrm{H}^{13} \mathrm{C}^{13} \mathrm{CH}$, a molecule of relevance to both experimental and theoretical chemistry. We have determined spectroscopic parameters concerning observed cold and hot bands from the experimental spectrum. These parameters will help researchers to better understand the energy level structure of this molecule.

We have proven the usefulness of our home-built CRD spectrometer in recording these data. Not only did the high sensitivity make it possible to observe weak bands, its high rate of data collection meant that it was not an inordinately slow process to do so. In the future, we intend to continue to improve the spectrometer, initially by making modifications to the existing model and then later to build a redesigned version. We believe that reversing the scanning mirror configuration, so that the piezo presses inwards on the end mirror rather than supporting its weight, will remove or diminish the slow baseline drift problem.

\section{Acknowledgements}

We are grateful to the Academy of Finland and the Finnish Centre of Excellence in Computational Molecular Science for financial support. JG acknowledges support from QUASAAR, a Marie Curie Research Training Network supported by the European Commission (Contract No. MRTN-CT-2004-512202).

\section{References}

[1] V. Ivanov, J.B. Nagy, Ph. Lambin, A. Lucas, X.B. Zhang, X.F. Zhang, D. Bernaerts, G. Van Tendeloo, S. Amelinckx and J. Van Landuyt, Chemical Physics Letters, 223 (1994) 329.

[2] W.Z. Li, S.S. Xie, L.X. Qian,B.H. Chang, B.S. Zou, W.Y. Zhou, R.A. Zhao, G. Wang, Science, 274 (1996) 1701.

[3] H. Safouhi and L. Berlu, Internet Electron. J. Mol. Des., 3 (2004) 728.

[4] M.J. Bramley, N.C. Handy, J. Chem. Phys., 98 (1993) 1378. 
Figure 2. A magnified portion of the spectrum shown in fig. 1. The two large peaks that have been truncated by the upper border of the figure belong to the cold transition. The rest have been assigned to hot bands. The only exception is marked with an asterisk. It belongs to a cold band of $\mathrm{H}^{12} \mathrm{C}^{13} \mathrm{CH}$, which was present as an impurity in the $\mathrm{H}^{13} \mathrm{C}^{13} \mathrm{CH}$ sample. The baseline drift in each of the $0.9 \mathrm{~cm}^{-1}$ scans can be seen at this magnification.

Table 1. Spectroscopic analysis of the vibration-rotation bands of $\mathrm{H}^{13} \mathrm{C}^{13} \mathrm{CH}$ observed in this study

\begin{tabular}{|c|c|c|c|c|c|c|c|c|}
\hline Upper state & & Lower state & $\Delta G\left(\mathrm{~cm}^{-1}\right)$ & $B^{\prime}\left(\mathrm{cm}^{-1}\right)$ & $10^{6} D^{\prime}\left(\mathrm{cm}^{-1}\right)$ & $10^{3} \Delta\left(\mathrm{cm}^{-1}\right)$ & $J_{\max }^{\prime \prime}$ & $N$ \\
\hline $3010^{\circ} 0^{\circ}(70 \%)\left(1030^{0} 0^{0}(28 \%)\right)$ & $\Sigma_{u}^{+}(\mathrm{e})$ & $0000^{0} 0^{0} \Sigma_{a}^{+}(\mathrm{e})$ & $12960.28807(38)$ & $1.0960176(15)$ & $1.4350(11)$ & 1.8 & 39 & 75 \\
\hline $3011^{1} 0^{0}(65 \%)\left(1031^{1} 0^{0}(26 \%)\right)$ & $\Pi_{u}(\mathrm{e})$ & $0001^{1} 0^{0} \Pi_{g}(\mathrm{e})$ & $12908.03290(92)$ & $1.0951256(99)$ & $1.341(20)$ & 2.8 & 22 & 39 \\
\hline $3011^{1} 0^{0}(65 \%)\left(1031^{1} 0^{0}(26 \%)\right)$ & $\Pi_{u}(\mathrm{f})$ & $0001^{1} 0^{0} \Pi_{g}(\mathrm{f})$ & $12908.0356(13)$ & $1.100176(15)$ & $0.977(34)$ & 3.8 & 23 & 35 \\
\hline $3010^{0} 1^{1}(64 \%)\left(1030^{0} 1^{1}(26 \%)\right)$ & $\Pi_{g}(\mathrm{e})$ & $0000^{0} 1^{1} \Pi_{u}(\mathrm{e})$ & $12918.1383(10)$ & $1.0958109(79)$ & $1.410(12)$ & 3.3 & 26 & 46 \\
\hline $3010^{0} 1^{1}(64 \%)\left(1030^{0} 1^{1}(26 \%)\right)$ & $\Pi_{g}(\mathrm{f})$ & $0000^{0} 1^{1} \Pi_{u}(\mathrm{f})$ & $12918.1373(10)$ & $1.1004158(77)$ & $1.514(11)$ & 3.1 & 26 & 43 \\
\hline $0040^{0} 1^{1}(46 \%)\left(2020^{0} 1^{1}(16 \%)\right)$ & $\Pi_{u}(\mathrm{e})$ & $0001^{1} 0^{0} \Pi_{g}(\mathrm{e})$ & $12959.7356(16)$ & $1.097482(17)$ & $1.960(34)$ & 3.1 & 21 & 22 \\
\hline $0040^{0} 1^{1}(46 \%)\left(2020^{0} 1^{1}(16 \%)\right)$ & $\Pi_{u}(\mathrm{f})$ & $0001^{1} 0^{0} \Pi_{g}(\mathrm{f})$ & $12959.7359(19)$ & $1.104707(28)$ & $1.285(83)$ & 4.2 & 19 & 29 \\
\hline
\end{tabular}

The lower-state rotational parameters are:

$0000^{0} 0^{0}$ state: $B^{\prime \prime}=1.119574687 \mathrm{~cm}^{-1}, D^{\prime \prime}=1.487382 \times 10^{-6} \mathrm{~cm}^{-1}, H^{\prime \prime}=1.2616 \times 10^{-12} \mathrm{~cm}^{-1}$.

$0001^{1} 0^{0}$ e state: $B^{\prime \prime}=1.1182056 \mathrm{~cm}^{-1}, D^{\prime \prime}=1.498400 \times 10^{-6} \mathrm{~cm}^{-1}$.

$0001^{1} 0^{0}$ f state: $B^{\prime \prime}=1.1230130 \mathrm{~cm}^{-1}, D^{\prime \prime}=1.531700 \times 10^{-6} \mathrm{~cm}^{-1}$.

$0000^{0} 1^{1}$ e state: $B^{\prime \prime}=1.11939372 \mathrm{~cm}^{-1}, D^{\prime \prime}=1.491541 \times 10^{-6} \mathrm{~cm}^{-1}$.

$0000^{0} 1^{1}$ f state: $B^{\prime \prime}=1.12365986 \mathrm{~cm}^{-1}, D^{\prime \prime}=1.524870 \times 10^{-6} \mathrm{~cm}^{-1}$.

The ground state $\left(0000^{0} 0^{0}\right)$ parameters are from ref. [21] and the parameters of the other states were calculated with equations in the same reference. Percentages in parentheses give the contribution of the state to the observed eigenstate. The quantity $\Delta$ is the standard deviation of the fit, $J_{\max }^{\prime \prime}$ is the largest lower-state angular momentum quantum number of the transitions included in the fit, and $N$ is the number of data included. Numbers in parentheses are errors from the fit and are one-standard errors in the least significant digits. 
Figure 3. The squared vibrational transition dipole moment for the $\mathrm{P}$ and $\mathrm{R}$ branches of the $3010^{0} 0^{0}$ (or (31-)) band. Errors for these measurements are estimated to be in the order of $10 \%$. Because the noise in the spectrum has an effect that is inversely proportional to the linestrength, the uncertainty is largest for the weak peaks, i.e. those on the far edges of the graph. The line is a linear least-squares fit of the data to eq. (4).

Table 2. Square moduli of the vibrational dipole moments for the observed hot bands. ${ }^{\text {a }}$

\begin{tabular}{lcc}
\hline$\Delta G\left(\mathrm{~cm}^{-1}\right)$ & Branch & $\left|R_{\mathrm{v}^{\prime} \mathrm{v}^{\prime \prime}}\right|^{2} / 10^{10} \mathrm{D}^{2}$ \\
\hline $12908 \mathrm{e}$ & $\mathrm{P}$ & 9.5 \\
& $\mathrm{R}$ & 8.9 \\
$12908 \mathrm{f}$ & $\mathrm{P}$ & 9.7 \\
& $\mathrm{R}$ & 8.9 \\
$12918 \mathrm{e}$ & $\mathrm{P}$ & 10 \\
& $\mathrm{R}$ & 10 \\
$12918 \mathrm{f}$ & $\mathrm{P}$ & 10 \\
& $\mathrm{R}$ & 11 \\
$12960 \mathrm{e}$ & $\mathrm{P}$ & $\mathrm{b}$ \\
& $\mathrm{R}$ & 4.4 \\
$12960 \mathrm{f}$ & $\mathrm{P}$ & 4 \\
& $\mathrm{R}$ & 4 \\
\hline
\end{tabular}

a See fig. 3 and the text for the cold band data.

b There were not enough usable data to obtain a meaningful value.

[5] L. Halonen, M.S. Child, S. Carter, Mol. Phys., 47 (1982) 1097.

6] M. Herman, A. Campargue, M.I. El Idrisi, J. Vander Auwera, J. Phys. Chem. Ref. Data, 32 (2003) 921.

[7] C. Vallance, New J. Chem., 29 (2005) 867.

[8] A. O'Keefe, D.A.G. Deacon, Rev. Sci. Instrum., 59 (1988) 2544

[9] M.D. Wheeler, S.M. Newman, A.J. Orr-Ewing, M.N.R. Ashfold, J. Chem. Soc. Faraday Trans., 94 (1998) 337.

[10] R.Z. Martinez, M. Metsälä, O. Vaittinen, T. Lantta, L. Halonen, J. Opt. Soc. Am. B, 23 (2006) 727.

[11] M. Metsälä, J. Guss, O. Vaittinen, R.Z. Martinez, L. Halonen, Chem. Phys. Lett., 424 (2006) 7.

[12] R.W.P. Drever, J.L. Hall, F.V. Kowalski, J. Hough, G.M. Ford, A.J. Munley, H. Ward, Appl. Phys. B, 31 (1983) 97.

[13] D. Romanini, A.A. Kachanov, N. Sadeghi, F. Stoeckel, Chem. Phys. Lett., 264 (1997) 316.

[14] D. Romanini, A.A. Kachanov, F. Stoeckel, Chem. Phys. Lett., 270 (1997) 538.

[15] X. Zhan, O. Vaittinen, E. Kauppi, L. Halonen, Rev. Sci. Instrum., 63 (1992) 5546.

[16] S. Gersternkorn, J. Verges, J. Chevillard, Atlas du Spectre d'absorption de la molecule d'iode, Laboratoire Aime-Cotton, CNRS II, Orsay, (1982).

[17] G. Herzberg, Molecular Spectra and Molecular Structure II. Infrared and Raman Spectra of Polyatomic Molecules, Van Nostrand, New York, (1945). 


\section{Molecular Physics}

[18] C. Depiesse, G. Di Lonardo, A. Fayt, L. Fusina, D. Hurtmans, S. Robert, F. Tamassia, J. Vander Auwera, A. Baldan, M. Herman, J. Mol. Spectrosc., 229 (2005) 137.

[19] J. Sakai, M. Katayama, J. Mol. Spectrosc., 154 (1992) 277.

[20] J.K. Holland, D.A. Newnham, I.M. Mills, M. Herman, J. Mol. Spectrosc., 151 (1992) 346.

[21] G. Di Lonardo, P. Ferracuti, L. Fusina, E. Venuti, J.W.C. Johns, J. Mol. Spectrosc., 161 (1993) 466.

$[22]$ G. Di Lonardo, L. Fusina, E. Venuti, J.W.C. Johns, M.I. El Idrissi, J. Lievin, M. Herman, J. Chem. Phys., 111 (1999) 1008.

[23] B.T. Darling, D.M. Dennison, Phys. Rev., 57 (1940) 128.

[24] I.M. Mills, A.G. Robiette, Mol. Phys., 56 (1985).

[25] R.R. Hall, Ph.D. thesis, Rice University, Houston, TX, (1984).

[26] J. Vander Auwera, J. Molec. Spectrosc., 201 (2000) 143.

[27] L.S. Rothman, R.L. Hawkins, R.B. Wattson, R.R. Gamache, J. Quant. Spectrosc. Radiat. Transfer, 48 (1992) 537.

[28] R. Herman, R.F. Wallis, J. Chem. Phys., 23 (1955) 637.

[29] R. El Hachtouki, J. Vander Auwera, J. Mol. Spectrosc., 216 (2002) 355. 


\section{Page 9 of 11}

\section{Molecular Physics}

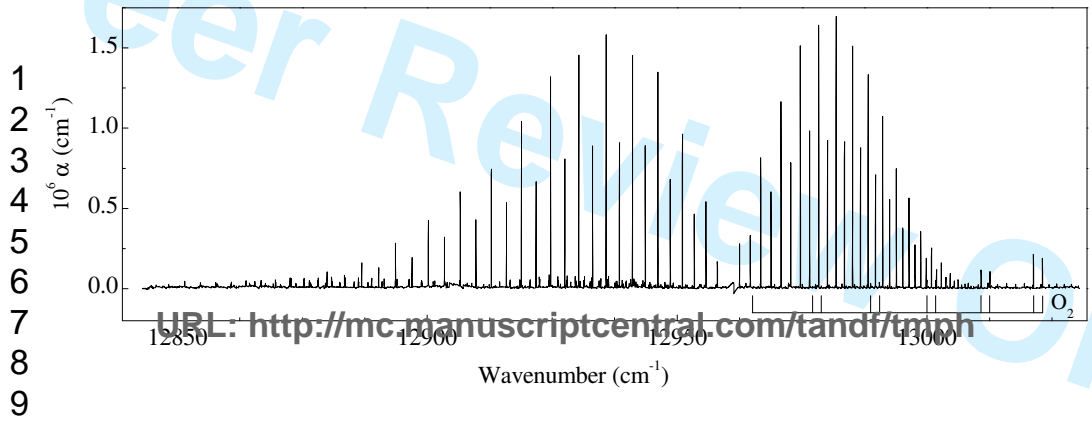




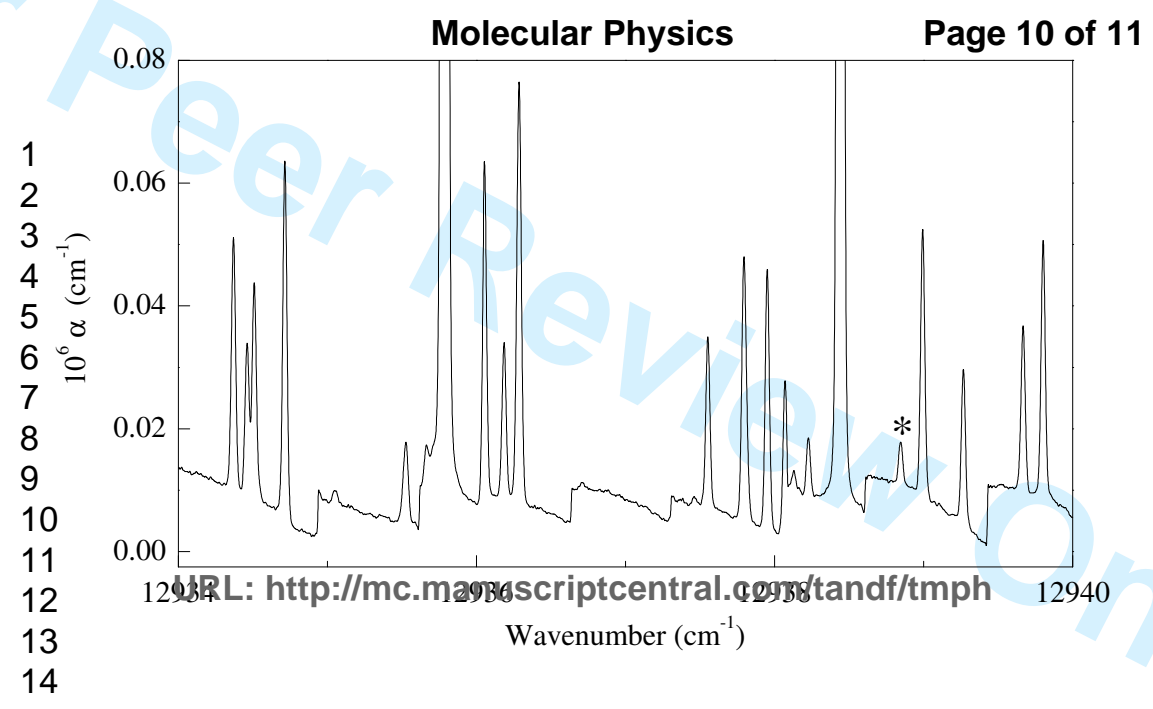




\section{Page 11 of $11 \quad$ Molecular Physics}

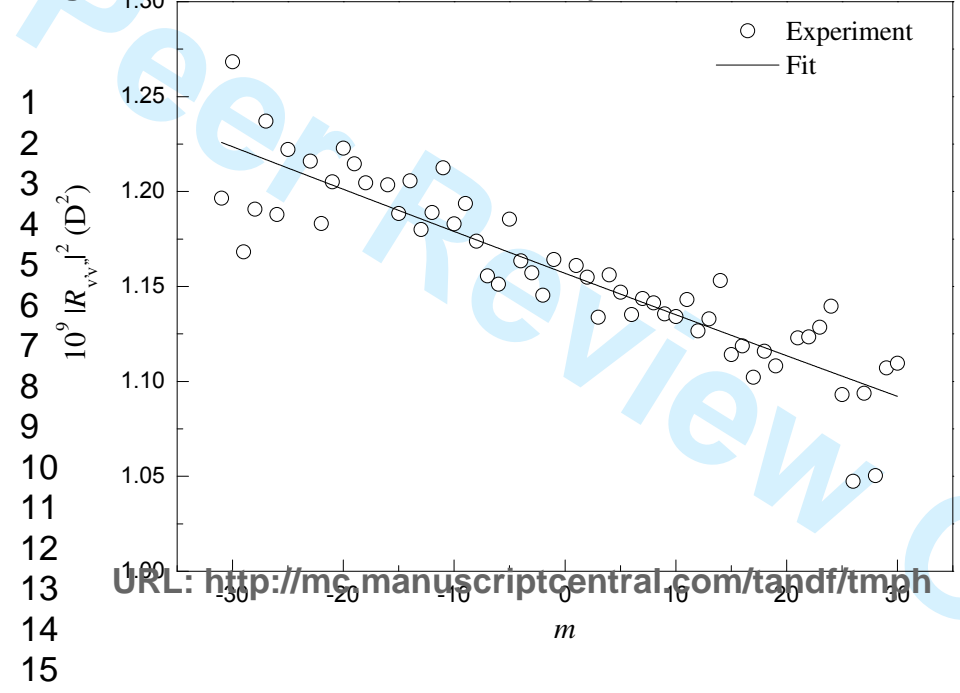

